\title{
ALGUNS APONTAMENTOS SOBRE A TESE VIII, DE WALTER BENJAMIN, EM SOBRE O CONCEITO DE HISTÓRIA
}

\author{
José Carlos Mariano do Carmo ${ }^{33}$
}

Resumo: Trata-se de uma breve exegese sobre alguns conceitos da obra benjaminiana, especialmente conceitos de memória, recordação, progresso e barbárie. $\mathrm{O}$ esquecimento utilizado como estratégia de defesa de regimes totalitários e a atualidade de Walter Benjamin ao solicitar que "se puxe os freios de emergência", a fim de evitar que haja mais mortos, mais oprimidos e mais injustiçados. $\mathrm{O}$ caminho continua difícil, pois há muitas ditaduras, muita miséria e exclusão. Os campos de concentração, que eram espaços fechados, parecem hoje abertos e os excluídos passeiam por megacidades, abandonados pelo sistema social, em atividades como, por exemplo, a de catadores, reciclando materiais que quase nada significam em termos de sobrevivência digna, mas que limpam a cidade das misérias do capitalismo, enquanto o sistema empurra as classes mais abastadas e médias para os templos de consumo e do esquecimento da História, com " $\mathrm{H}$ " maiúscula para se diferenciar do historicismo, este que conta a história de forma mecânica como um relógio, calculando matematicamente a ordem das datas e a lista dos vencedores, gerando muita empatia pelo mais forte. Essa perversa lógica de progresso, que avança como um caranguejo, fazendo diariamente milhões de vítimas e mortos, assolados por falta de condições mínimas de vida e muitas ainda são vítimas de armamentos cada vez mais sofisticados, químicos e/ou nucleares. Diariamente temos o crime hermenêutico do esquecimento das vítimas da História, em que os mortos jazem nas covas, mas continuam a clamar por justiça.

Palavras-chave: Walter Benjamin; Recordação; Esquecimento; Progresso; Barbárie.

Abstract: It is a brief exegesis on some concepts of the benjaminiano work, especially concepts of memory, memory, progress and barbarism.

33 Doutor em Teoria Literária pela Universidade Federal de Santa Catarina (UFSC). Professor da Faculdade Educacional da Lapa (FAEL). 
The oblivion used as a defence strategy for totalitarian regimes and the current situation of Walter Benjamin in requesting that "pull the emergency brakes" in order to avoid that there are more dead, more oppressed and more wronged. The road remains difficult, as there are many dictatorships, much misery and exclusion. The concentration camps, which were enclosed spaces, seem open today and the excluded go through megacities, abandoned by the social system, in activities such as garbage collectors, recycling materials that mean almost nothing in terms of dignified survival, but which cleans the city from the miseries of capitalism, while the system pushes the more affluent and average classes into the temples of consumption and forgetting history, with a capital " $\mathrm{H}$ to differentiate itself from historicism, which tells the story mechanically as a clock, mathematically calculating the order of dates and the list of winners, generating much empathy for the strongest. This perverse logic of progress, which advances like a crab, daily making millions of victims and dead, desolated by lack of minimum conditions of life and many are still victims of increasingly sophisticated, chemical and / or nuclear weapons. Daily we have the hermeneutic crime of forgetting the victims of history, in which the dead lie in the graves, but continue to call for justice.

Keywords: Walter Benjamin; Remembrance; Forgetfulness; Progress; Barbarism.

As questões mundiais e a possibilidade instalada de uma guerra nuclear e química requerem um arcabouço teórico para, na feliz expressão de Walter Benjamin, "puxar os freios de emergência". A situação geopolítica atual é extremamente complicada e se pensarmos nos direitos humanos, podemos perfeitamente parafrasear Benjamin e afirmar que sempre teremos posições a defender no mundo a favor dos oprimidos. ${ }^{34}$ Concordamos com o pensamento benjaminiano, ou seja, o combate ao fascismo, ao nazismo e a todos os regimes totalitários pode ser perfeitamente compreendido pelo cenário atual que, sem muito esforço pode ser visualizado numa das batalhas atuais, a qual demonstra o império norte-americano de um lado e a Coréia do Norte do outro, numa

\footnotetext{
${ }^{34}$ A frase de Walter Benjamin é “Ainda há posições a defender na Europa” em relação ao fascismo e ao nazismo, em carta ao amigo Theodor Wisengrund Adorno, em 1938.
} 
possibilidade concreta de bombardeio nuclear, apenas para ficarmos num exemplo sobre a atualidade de Benjamin em que a guerra pode "[...] destruir todas as formas de vida humana, animal ou vegetal num vasto território." (BENJAMIN, 2013, p.10).

Com suas mazelas, desigualdades e massacre às minorias, podemos inserir o Brasil e muitas outras partes do mundo, na frase de Benjamin que afirma que "o progresso avança como um caranguejo" e, ainda, que "[...] todos esses progressos se dão sobre as costas de uma parte da humanidade." (BENJAMIN apud MATE, 2011, p. 11). Se no contexto mundial tínhamos os horrores dos campos de concentração da segunda guerra, com nazistas e fascistas, hoje temos não apenas Guantánamo, mas inúmeros sentidos ampliados para o que seja campo, que não apenas os de concentração: campo de desempregados; campo de indígenas, campo de refugiados, apátridas e muitos outros.

Vejamos, então, o que afirma a Tese VIII em Sobre o conceito de História, de Walter Benjamin:

Cumplicidade entre progresso e fascismo ou por que os oprimidos vivem em permanente estado de exceção

A tradição dos oprimidos nos ensina que o "estado de exceção" em que vivemos é a regra. Devemos chegar a um conceito de história que corresponda a essa situação. Nossa tarefa histórica consistirá, então, em suscitar a vinda do verdadeiro estado de exceção, melhorando assim nossa posição na luta contra o fascismo. O fato de seus adversários o enfrentarem em nome do progresso, tomando este por lei histórica, não é exatamente a menor das chances do fascismo. Não tem nada de filosófico assombrar-se pelo fato de as coisas que estamos vivendo "ainda" serem possiveis em pleno século XX. É um assombro que não nasce de um conhecimento, a não ser deste: que não se sustenta a ideia de história que provoca assombro. (BENJAMIN apud MATE, 2011, p. 187).

O progresso é, sem dúvida, uma lei histórica. Isto não quer dizer que Walter Benjamin recuse os avanços tecnológicos quando estes têm a função de melhorar nossas condições de existência. $\mathrm{O}$ que se pretende é questionar a fé cega na crença obstinada de armas nucleares ou químicas, em que civis são mortos sem qualquer crise de consciência. Ao mesmo 
tempo, especialmente com a chamada "precarização da ética", os escombros se multiplicam e os mortos são esquecidos no lixo da história. O historiador benjaminiano é aquele catador e revolve os escombros, procurando as vítimas que precisam ser relembradas, colocando o assunto como pauta inadiável de debate e de memória coletiva, em que "nenhum", absolutamente nenhum crime passe despercebido. A luta contra o fascismo continua, porque fascistas sempre existirão na face da terra. A luta contra as ditaduras e seus tiranos também. A História aberta quer reabrir os arquivos secretos e tem consciência de que não irá assombrar-se com as barbáries cometidas, em pleno século XXI, assim poderíamos dizer.

Os regimes totalitários se multiplicam não apenas na crença obstinada pela tecnologia, ostentando armamentos nucleares em desfiles homéricos, mas também na indiferença com o sofrimento de milhões de seres humanos, num verdadeiro "apartheid" mundial, especialmente para os refugiados pela guerra e pela fome. Se por um lado temos a confiança cega no progresso tecnológico, por outro lado temos também a "precarização da ética" como conduta, sendo extremamente emblemáticos que os párias sociais do mundo sejam também os oprimidos que vivem em estado de exceção permanente. Todos os progressos tecnológicos, alardeados aos quatro cantos, viraram as costas aos direitos de milhões de seres humanos: "[...] as guerras produzem mortos e a riqueza, miséria". (MATE, 2011, p. 11).

Walter Benjamin dedicou um estudo no chamado konvolute " $\mathrm{N}$ Teoria do Conhecimento, teoria do progresso" que está na obra Passagens, em que o conceito de progresso é fundamentado na ideia de catástrofe. Não por acaso, o "Angelus Novus”, de Paul Klee, obra de 1933, aparece no coração das teses, ou seja, a Tese IX, que trata justamente desse aspecto:

A figura de Klee, o Angelus Novus, é a expressão da tarefa do historiador para Benjamin. Olhos no passado, vê ruínas onde o historicista veria acontecimentos, vê catástrofes onde o historicista conta vitórias. Não pode recolher os destroços porque é impelido para o futuro, isto a que o historicista chama progresso (MURICY, 2009, p. 233).

A figura maravilhosa do pintor Paul Klee, Angelus Novus, grita estarrecida com os olhos revirados para o passado, em que veem 
injustiçados e assassinados, em que os escombros parecem seguir até o infinito do céu e, também, os olhos no presente, em que com as mãos abertas parece questionar-se: como melhorar as condições reais de existência dos seres humanos no mundo? Como evitar que tais barbáries se repitam? Já não há espaços para fuga e o mar de incertezas parece infinito. Muitos africanos e refugiados pela guerra morrem no trajeto pela sobrevivência, perseguidos pela fome, por guerras religiosas ou por governos totalitários que querem se manter no poder, ad infinitum.

Também podemos ler claramente, em Passagens, a frase de Strindberg em "Rumo a Damasco": "o inferno não é aquilo que nos aguarda, e sim esta vida aqui”. (BENJAMIN, 2009, p. 515). Vivemos uma continuidade de história reificada em que o progresso é para poucos, enquanto a maioria "[...] permanece em uma condição perene de incultura (Umbildung) [...]". (BENJAMIN, 2009, p. 522). Além da questão perene da incultura e ignorância, há a falta quase total de ética por parte da classe dirigente e política.

Para exemplificar o estado iminente de catástrofe a que alude o "Anjo da História", da TESE IX, poderíamos citar a possibilidade de guerra, por decisão do presidente Donald Trump e/ou do norte-coreano Kim Jong-Un. Ambos exibem suas armas cada vez mais potentes e que podem atravessar a terra de uma ponta à outra, em que pese recuos e avanços nas negociações pela paz e pela civilidade. Ainda assim há uma fé cega na lógica do progresso, em que o mensageiro da desgraça anuncia que a terra está em perigo. Vale ressaltar que o conceito de guerra é bem diferente do conceito de invasão. Na guerra declarada mutuamente, os países envolvidos têm ciência das consequências letais que poderão advir. Já na invasão, segundo Reyes Mate, não se reconhece o país invadido como nação, mas como um país a ser escravizado. Como exemplo, podemos citar a invasão que os EUA fizeram no Iraque. Ao invadir com ataques sistemáticos esse país, o governo dos EUA tornou uma nação inteira escrava do seu poder imperialista: para os norte-americanos o estado de direito é permanente, para os de outras nações, especialmente os de origem muçulmana, não há mediação possível e o que entra em ação é o estado de exceção. Se numa guerra existe a possibilidade de reação, ainda mínima que seja, na invasão, o outro país, o invadido, não tem qualquer direito a não ser o de ser escravizado. Não por acaso, uma das principais células do Estado Islâmico, em decorrência do fim da $\mathrm{Al}$ Qaeda, surgiu no Iraque, estendendo-se até a Síria, país este em que o 
ditador Bashar Al-Assad utilizou-se do gás sarin para atacar civis. É desse mundo insano que surge a necessidade, segundo Benjamin, de organizarmos o pessimismo revolucionário, ativo, capaz de interferir e mudar o próprio rumo dos projetos que são sancionados como sendo fracassados:

Desnecessário dizer que não se trata de um sentimento contemplativo e fatalista, mas de um pessimismo ativo, 'organizado', prático, inteiramente voltado para o objetivo de impedir, por todos os meios possíveis, o advento do pior (LÖWY, 2002, p. 49, grifos do autor).

Não obstante, a teoria benjaminiana não se pretende explicar sob o viés dos poderosos e sim dos oprimidos pela própria história e, principalmente, pelo lumpemproletariado, este que vive em constante perigo, onde o que se chama de progresso é um "[...] processo em ruínas e cadáveres [...]" (MATE, 2011, p. 17). O historicismo estuda o passado muito mais como um turista, sem se preocupar com a História dos vencidos e dos escombros deixados, além dos inúmeros projetos pessoais ou coletivos frustrados e esmagados pela própria história. Precisamos ser anamnésicos no sentido de estímulo à memória, pois,
A recordação tem por objeto resgatar do passado o direito à justiça ou, caso se prefira, reconhecer no passado dos vencidos uma injustiça ainda vigente, isto é, ler os projetos frustrados de que está semeada a história, não como custos do progresso, mas como injustiças pendentes (MATE, 2011, p. 28).

A política não é assunto apenas dos vivos, mas também dos mortos que continuam reivindicando direito à reparação. Para Benjamin, ao contrário da crítica de Horkheimer, embora de fato os mortos estejam mortos, suas reivindicações continuam latentes e os arquivos precisam ser reabertos. A lógica do esquecimento pode ser bem entendida quando os regimes militares, especialmente na América do Sul, trataram de desaparecer com os mortos que não poderiam, em hipótese alguma, reaparecer como fantasmas de justiça. Para os poderosos, esquecer é preciso, sempre, e sem deixar rastros. 
Para Benjamin, a ordem profana requer a felicidade dos vivos; já a ordem messiânica requer a felicidade dos mortos. A teologia sozinha não dá conta dos escombros passados. A teoria do conhecimento benjaminiano propõe a união entre o marxismo heterodoxo e a teologia. Não se trata mais do marxismo ortodoxo, mas daquele que se apropria dos conceitos teológicos para fazer justiça. A pergunta é: será que a recordação apenas reconheceria as injustiças passadas? Não seria esta uma situação aporética da teoria do conhecimento de Walter Benjamin? Talvez como resposta provisória seja necessária a afirmação de que uma teoria do conhecimento "poderá" se questionar e ser inconclusiva constantemente. Se não conseguirmos reparar as injustiças passadas para com os mortos, poderemos perfeitamente evitar que tais injustiças se repitam, por meio da memória/recordação. Quando a morte de um ser humano inocente ganha contornos de memória coletiva, reivindicada, por exemplo, o que se quer é justiça para os casos de assassinatos provocados por regimes totalitários ou grupos militares e paramilitares. A morte de um ser humano oprimido pode e deve servir como ponto de partida para a ampliação da luta contra os opressores, em que a memória individual passa a ser coletiva:

Contudo, se a memória coletiva tira sua força e sua duração por ter como base um conjunto de pessoas, são os indivíduos que se lembram, enquanto integrantes do grupo. Desta massa de lembranças comuns, umas apoiadas nas outras, não são as mesmas que aparecerão com maior intensidade a cada um deles. De bom grado, diríamos que cada memória individual é um ponto de vista sobre a memória coletiva, que este ponto de vista muda segundo o lugar que ali ocupo e que este mesmo lugar muda segundo as relações que mantenho com outros ambientes. Não é de surpreender que nem todos tirem o mesmo partido do instrumento comum. Quando tentamos explicar essa diversidade, sempre voltamos a uma combinação de influência que são todas de natureza social (HALBWACHS, 2006, p. 69).

O crime hermenêutico é "esquecer" que os mortos injustiçados e oprimidos continuam vivos em suas reivindicações, estas que "deveriam" 
ser reparadas, seja para as gerações do presente, seja para as gerações futuras. Torna-se assim um imperativo categórico no sentido de "reorientar o pensamento e a ação para que Auschwitz não se repita". E é muito pertinente o questionamento de Reyes Mate: "[...] os genocídios, as ditaduras e a injustiça social se repetiram e continuam campeando por seus lucros, será por que não basta a memória ou por que não temos recordado bem?" (MATE, 2011, p. 33).

As tecnologias, ao invés de liberar o ser humano para atividades do pensamento, transformam-no numa parte da engrenagem. Se no início da era industrial tínhamos o fetiche pela mercadoria, já perdidos e sem saber como eram feitas e produzidas, hoje estamos num santuário fantasmagórico, porque compramos muitas vezes não por necessidade, mas por prestígio social. Portanto, a diferença entre o fetiche e a fantasmagoria não está na produção, mas nas vitrines. $O$ centro de atenção não é mais a fábrica ou o lugar de produção, mas a vitrine ou o lugar de consumo. A fantasmagoria nos apresenta uma mercadoria como se ela não tivesse passado por um mecanismo de produção. Torna-se ainda maior essa distância quando pensamos no mundo virtual de compras pela Internet: "A enxurrada de informações precisas e diversões assépticas, desperta e idiotiza as pessoas ao mesmo tempo" (ADORNO; HORKHEIMER, 1985, p. 14). É por isso, como bem afirma Reyes Mate, que a roupa se converte na "exteriorização da marca de prestígio social, seu sentido não é utilizá-lo como vestimenta de abrigo, mas responder ao sonho ideal que representa." (MATE, 2011, p. 49).

Além do exposto, não se pode dissociar o progresso da barbárie, em que a própria teoria darwinista pode ser questionada na sobrevivência e capacidade de adaptação do mais forte, especialmente quando se trata de seres humanos e o que vemos no mundo são vencedores escrevendo suas histórias: "O mal do progresso é o esquecimento." (MATE, 2011, p. 52). É também por isso que temos tantos campos de exclusão, pois "Os pobres estão sobrando, não são necessários para o progresso.” (MATE, 2011, p. 53). Do ponto de vista histórico, conforme Benjamin, citado por João Barrento: "É mais difícil honrar a memória dos anónimos do que a dos famosos. A construção da história é dedicada aos anónimos" (BENJAMIN apud BARRENTO, 2013, p. 156).

Com relação ao que poderia ter sido e não foi, poderíamos perfeitamente efetuar o seguinte questionamento: como teria sido o Brasil se o governo Jango não tivesse sofrido um golpe militar? Ao mesmo tempo poderíamos pensar no Chile, com Allende. Os esmagados pela 
história opressora, com dezenas de milhares de desaparecidos, continuam clamando por justiça. É perfeitamente plausível procurar entender como tais democracias atuais tratam a memória de seus antepassados injustiçados e poderíamos efetuar uma reflexão em como os países Argentina, Chile e Brasil, para ficarmos apenas em alguns exemplos, tratam de julgar e reparar as injustiças de tais oprimidos e desaparecidos. A atenção se volta para o presente, num passado que ressurge, que grita, que berra e pede justiça. O Memorial "Parque La Memoria", inaugurado em 2007 em Buenos Aires, diz muito sobre as perspectivas de resgate histórico nesses países. Aliás, o memorial passa a representar uma pequena parte da reparação aos injustiçados e, de alguma forma, relembra às gerações do presente o palco de horrores praticados por tiranos $\mathrm{e}$ ditadores ou, ainda e no templo capitalista, os praticados pela "roda mundo roda gigante roda moinho roda pião", num desenfreado consumo mediado pelo deus monetário, em que as classes abastadas pouco se importam com os menos favorecidos.

Muitas vítimas de atrocidades ainda morrerão em decorrência de barbáries e muitas sociedades "civilizadas" certamente vão querer esquecer tais atrocidades, sem julgar os culpados e sem tornar palpável fisicamente a memória dos assassinados e desaparecidos, para que todos nós esqueçamos o mais rápido possível e que fiquemos alienados, pois assim se repete a volta ao "eterno retorno" dos ditadores e dos assassinos. E o estado de direito sucumbirá novamente, num estado permanente de exceção, sem mediação possível. A tempestade poderá acabar com todas as formas de vida que não serão as da natureza generosa, mas a barbárie dos próprios seres humanos, orando para que venha mais dinheiro, seja com bombas nucleares, seja com armas químicas ou, ainda, com a promessa de esquecimento por parte de todos.

É emblemático, no Brasil e para citarmos um exemplo atualíssimo, o caso da vereadora do PSOL Marielle Franco, assassinada com uma saraivada de tiros, advindos provavelmente de atiradores de elite, inclusive com silenciador. Atém o momento, não há qualquer revelação por parte da polícia nas investigações para que os assassinos sejam revelados. As milícias que comandam o tráfico de drogas e armamentos no Rio de Janeiro, a cidade maravilhosa, têm ligações políticas com esquadrões militares. A morte de Marielle Franco, mulher negra da favela que enfrentou os poderosos com suas ideias, é vergonhosa para o Brasil. Ela passa a ser símbolo de nossa memória coletiva e não poderá ser jamais 
esquecida. As balas da metralhadora que assassinaram covardemente a vereadora, não apagarão as ideias de justiça dela. É, sem dúvida, um crime político. No Brasil, um país, como tantos outros, da impunidade, quantos mais assassínios poderão acontecer? E os assassinos fazem de tudo para achar o "ponto cego" das câmeras de vigilância, apagando qualquer vestígio de identificação. Teremos que lutar muito para que os crimes não caiam no esquecimento!

E todos os assassinos querem apagar os vestígios. Em relação a isso, Bertolt Brecht tem um poema chamado "Guia para o habitante das cidades”, em que o refrão é na tradução de Jeanne Marie Gagnebin: "Apague os rastros". Vejamos:

Claro, a citação do poema de Brecht também possui um valor crítico de denúncia porque evoca, de maneira simultaneamente sóbria e profética, as práticas do Estado totalitário moderno. Cito as duas primeiras estrofes:

O que você disser, não diga duas vezes.

Encontrando seu pensamento em outra pessoa: negue-o.

Quem não estava presente, quem nada falou

Como poderão apanhá-lo?

Apague os rastros!

Cuide, quando pensar em morrer

Para que não haja sepultura revelando onde jaz

Como uma clara inscrição a lhe denunciar

E o ano de sua morte a lhe entregar

Mais uma vez:

Apague os rastros!

Assim me foi ensinado. (GAGNEBIN, 2006, p. 52).

É preciso afirmar que o estribilho "Apague os rastros" tanto pode servir aos revolucionários, na fuga insana para fugir de seus algozes, quanto para os tiranos. Aliás, dado ao conjunto do que até agora foi analisado neste breve ensaio, é possível afirmar que são os tiranos, os ditadores, os armamentistas que estão ganhando a batalha, acirrando ainda mais as desigualdades sociais no mundo. Estão vencendo a batalha 
para que os assassinos continuem soltos, a fim do "eterno retorno" das barbáries.

Se os tiranos querem a diversão e o esquecimento, num crime hermenêutico histórico, cabe aos historiadores relembrar, rememorar, recordar as vítimas constantes, assassinadas a queima roupa, sem direito a defesa. É preciso que haja o resgate histórico de tais vítimas:

Esse narrador sucateiro (o historiador também é um Lumpensammler não tem por alvo recolher os grandes feitos. Deve muito mais apanhar tudo aquilo que é deixado de lado como algo que não tem significação, algo que parece não ter nem importância nem sentido, algo com que a história oficial não sabe o que fazer. $O$ que são esses elementos de sobra do discurso histórico? A resposta de Benjamin é dupla. Em primeiro lugar, o sofrimento, o sofrimento indizivel que a Segunda Guerra Mundial levaria ao auge, na crueldade dos campos de concentração (que Benjamin, aliás, não conheceu graças ao suicídio). Em segundo lugar, aquilo que não tem nome, aqueles que não têm nome, o anônimo, aquilo que não deixa nenhum rastro, aquilo que foi tão bem apagado que mesmo a memória de sua existência não subsiste - aqueles que desapareceram tão por completo que ninguém lembra de seus nomes. Ou ainda: o narrador e o historiador deveriam transmitir o que a tradição, oficial ou dominante, justamente não recorda. Essa tarefa paradoxal consiste, então, na transmissão do inenarrável, numa fidelidade ao passado e aos mortos, mesmo - principalmente - quando não conhecemos nem seu nome, nem seu sentido (GAGNEBIN, 2006, p. 54, grifos meus).

O que gostaríamos é que nenhuma vítima injustiçada e oprimida do passado ficasse no esquecimento. Há tanta vítima no Brasil e no mundo que a relação seria extensa, infinitamente extensa.

Há guerras sem limites para a barbárie e há guerras para que haja o esquecimento completo das vítimas e como afirma Giorgio Agamben "o campo é o espaço que se abre quando o estado de exceção começa a converter-se em regra". (AGAMBEN apud MATE, 2011, p. 198). Há 
cumplicidade entre o progresso e a barbárie e é lamentável que esse progressismo e a leitura histórica a partir dos vencedores reduzam as possibilidades de rememoração dos assassínios constantes contra não apenas os oprimidos em que: "Há segmentos sociais para os quais a ordem estabelecida é a miséria estabilizada." (Einbahnstraße, GS IV, p. 926 apud MATE, 2011, p. 190).

Fazer referência às vidas, aos seus nomes, à sua dignidade de vítimas dos ditadores e tiranos, seja pela guerra, pelo poder, pelo tráfico de drogas e de armas, é obrigação mínima enquanto seres humanos, em que o pessimismo deve servir à luta revolucionária de maneira organizada.

E que não nos assombremos que numa época de tantos progressos, acontecem tantas barbáries, com vítimas civis e políticas desaparecidas pela bala, pela arma química, pela indiferença capitalista, pela desigualdade social, pelo descaso com o coletivo, pelo fanatismo armamentista, pelo preconceito racial, étnico, religioso, de gênero e de orientação sexual e continua campeando cada vez mais, cada vez mais, vítimas. Não há assombro que em pleno século XXI, a história e o historicismo se repetem e a leitura se faz, ainda, pela lente dos vencedores, justamente no Brasil, cuja divisa da bandeira nacional é: Ordem e Progresso!

\section{REFERENCIAS}

ADORNO, Theodor W; HORKHEIMER, Max. Dialética do esclarecimento: fragmentos filosóficos. Rio de Janeiro: Jorge Zahar Ed., 1985.

BARRENTO, João. Limiares sobre Walter Benjamin. Florianópolis: Ed. Da UFSC, 2013.

BENJAMIN, Walter. Experiência e pobreza. In: Magia e técnica, arte e política. São Paulo: Braziliense, 1994, p. 114-119.

. O capitalismo como religião. São Paulo: Boitempo, 2015.

. Passagens. Belo Horizonte: Editora UFMG; São Paulo: Imprensa Oficial de São Paulo, 2009.

. Reflexões sobre a criança, o brinquedo e a educação. São Paulo: Duas Cidades, 2002.

GAGNEBIN, Jeanne Marie Gagnebin. Lembrar escrever esquecer. São Paulo: Ed. 34, 2006. 
HALBWACHS, Maurice. A memória coletiva. Tradução de Beatriz Sidou. São Paulo: Centauro, 2006.

LÖWY, Michael. Walter Benjamin: aviso de incêndio uma leitura das teses "Sobre o conceito de história". São Paulo: Boitempo, 2005.

A estrela da manhã: surrealismo e marxismo. Rio de Janeiro: Civilização Brasileira, 2002.

MATE, Reyes. Meia-noite na história: comentários às teses de Walter Benjamin "Sobre o conceito de história". São Leopoldo, RS; UNISINOS, 2011.

MURICY, Katia. Alegorias da dialética: imagem e pensamento em Walter Benjamin. Rio de Janeiro: Nau, 2009.

WEBER, Max. A ética protestante e o espírito capitalista. São Paulo: Martin Claret, 2002.

Recebido em: 10/03/2018

Aceito em: 20/04/2018 